\title{
Influence of Combine Vertical Irregularities in the Response of Earthquake Resistance Rc Structure
}

\author{
Rupesh R. Pawade ${ }^{1}$, Dr.M.N.Mangulkar ${ }^{2 *}$ \\ ${ }^{1}$ PG Student, Jawaharlal Nehru College of Engineering, BAMU University, Aurangabad (M.S), 431003, India \\ ${ }^{2}$ Asst. Prof. Civil Engg. Department, Jawaharlal Nehru College of Engineering, BAMU University, Aurangabad
}

(M.S), 431003, India

\begin{abstract}
This study investigates the effect of frame set-back with vertical irregularity in height on accuracy of Pushover Analysis for predicting target displacement, story drifts, base shear and performance point. The behavior of high rise building during strong earthquake motion depends on the distribution of mass, stiffness and strength in both horizontal and vertical planes of the buildings. The Indian IS code 1893:2002(Part 1) has pointed out of different structures irregularities like plan irregularity and vertical irregularity. In this study the seismic performance of G+ 16 storey having combine effect of vertical irregularity with R.C building are examined using Non Linear Static Analysis (Pushover Analysis). The Base shear, lateral displacement, storey drift and performance points are the response parameters use to quantify the performance of the structure. These irregularities are responsible for structural collapse of buildings under the action of dynamic loads. Five different types of building geometry are taken one regular and four irregular frames. The all buildings are modeled and analyzed in software SAP 2000. It was found that irregularity in elevation of the building reduce the performance level of structure.
\end{abstract}

Keywords: Base shear, Lateral displacement, Non-Linear static analysis, Performance point, Seismic performance, R.C. building, Vertical irregularity, etc..

\section{Introduction}

Over the past decades and more it has been recognized that damage control must become a more explicit design consideration which can be achieved only by introducing some kind of nonlinear analysis into the seismic design methodology. A building is said to be a regular when the building configurations are almost symmetrical about the axis and it is said to be the irregular when it lacks symmetry and discontinuity in geometry, mass or load resisting elements. Asymmetrical arrangements cause a large torsion force. IS 1893: 2002 (part1) has explained building configuration system for better performance of RC buildings during earthquakes. The building configuration has been described as regular or irregular in terms of the size and shape of the building, arrangement of structural the elements and mass. There are two types of irregularities 1) Horizontal irregularities refers to asymmetrical plan shapes (L, T, U and F) or discontinuities in horizontal resisting elements such as re-entrant corners, large openings, cut outs and other changes like torsion, deformations and other stress concentrations, 2) Vertical irregularities referring to sudden change of strength, stiffness, geometry and mass of a structure in vertical direction. The main objective of the present work is to study the response of the irregular structures under dynamic loads. In this present study it is proposed to consider the building frames that are irregular in elevation and plan analyze the response and behavior of the structures under earthquake. For this purpose, five RC building frames are selected and it is proposed to analyze all the frames that are considered and are modeled. SAP 2000 analysis package is proposed for the analysis of all structures, to get the all displacements, base shear, time period and performance point. Frames considered in this study are G+16 Storey 3-D frames. It is proposed that the responses of all the above frames are to be determined for all the load combinations. Lateral loads and Storey shears of all the four frames due to earthquake loads is proposed to determine using Non-linear static analysis method (Pushover).

The simplified approaches for the seismic evaluation of structures, which account for the inelastic behaviour, generally use the results of static collapse analysis to define the inelastic performance of the structure. Currently, for this purpose, the nonlinear static procedure (NSP) or pushover analysis described in FEMA-273, ATC-40 documents are used. However, the procedure involves certain approximations and simplifications that some amount of variation is always expected to exist in seismic demand prediction of pushover analysis. The widely used simplified nonlinear analysis procedure, pushover analysis, has also an attractive subject of study which is mainly appropriate for structures in which higher modes are not predominant, which are not influenced by dynamic characteristics. Although, pushover analysis has been shown to capture essential structural response characteristics under seismic action, the accuracy and the reliability of pushover analysis in predicting global and local seismic demands for all structures have been a subject of discussion. 


\section{Objectives}

The main objectives of this work includes the following,

1) To obtain the response of G+16 storey RC frame structure i.e., base shear and lateral displacement and performance point by pushover analysis. Modeling and analysis are achieved using SAP 2000 software.

2) The combine effect of vertical irregularities i.e., mass, stiffness and vertical setbacks are studied.

3) Non linear static static analysis method is conducted for zone-V according to IS 18932002 (Part 1) for medium soil type (type II).

4) All the five models are studied and analyzed using pushover analysis.

\section{Parametric Study}

A reinforced concrete frame with $17(\mathrm{G}+16)$ storey of dimension $24 \mathrm{mx} 18 \mathrm{~m}$, has been taken for seismic analysis. Six building models with combine effect of vertical irregularities are considered for comparison:

Model-1: Regular building.

Model-2, 3, 4, 5: Mass + Stiffness + Vertical setbacks

These five building models are analyzed for the following case

a) Using equivalent static lateral force method for zone-V for soil type-II (Medium soil) as per IS 1893(part 1):2002.

b) Using Pushover analysis.

\subsection{Preliminary Assumed data of $\mathbf{G + 1 6}$ RC frame:}

\begin{tabular}{|l|l|}
\hline Descriptions of Building & Special Moment Resisting Frame [SMRF] \\
\hline Structure type & $24 \mathrm{X} 18 \mathrm{~m}$ \\
\hline Plan dimension & $150 \mathrm{~mm}$ \\
\hline Slab thickness & $\begin{array}{l}1 . \text { For residential floor }=3.0 \mathrm{~m} \\
2 . \text { For commercial floor }=3.5 \mathrm{~m}\end{array}$ \\
\hline Storey height & G+16=17 storeys \\
\hline Height of building & M20 \\
\hline Grade of concrete & Fe 500 \\
\hline Grade of steel & $230 \times 550 \mathrm{~mm}$ \\
\hline Column size & $230 \times 600 \mathrm{~mm}$ \\
\hline Beam size & $18 \mathrm{Kn} / \mathrm{m} 3$ \\
\hline Density of Brickwall & $150 \mathrm{~mm}$ \\
\hline Thickness of Wall & $2.0 \mathrm{Kn} / \mathrm{m} 2$ \\
\hline Live load & $1.0 \mathrm{Kn} / \mathrm{m} 2$ \\
\hline Floor finish & $5.0 \mathrm{Kn} / \mathrm{m} 2$ \\
\hline Commercial loading for Mass irregularity & Zone V \\
\hline Seismic zone & 0.36 \\
\hline Zone factor & Type $2($ Medium soil $)$ \\
\hline Soil type & 1 \\
\hline Importance factor & 0.05 \\
\hline Damping ratio & $5.0(\mathrm{SMRF})$ \\
\hline Response reduction factor &
\end{tabular}

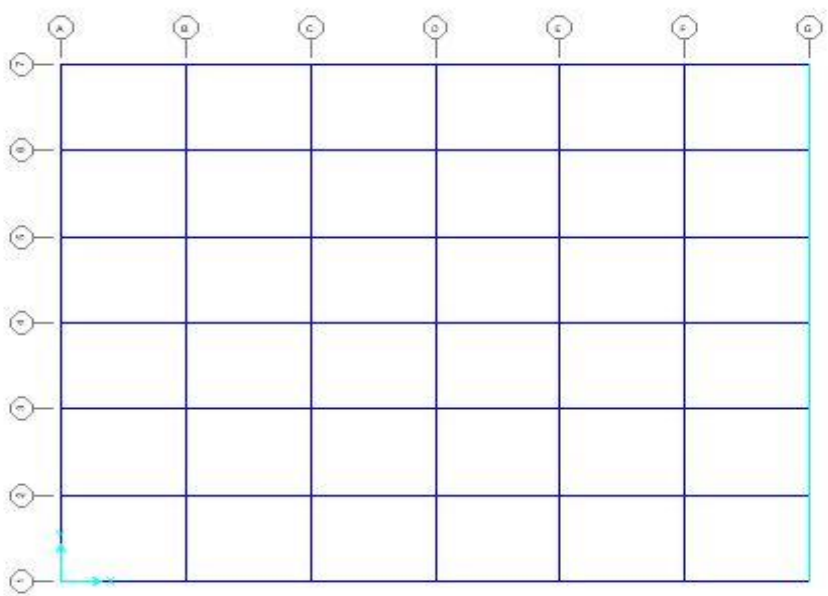

Fig. 1- Plan of regular building 


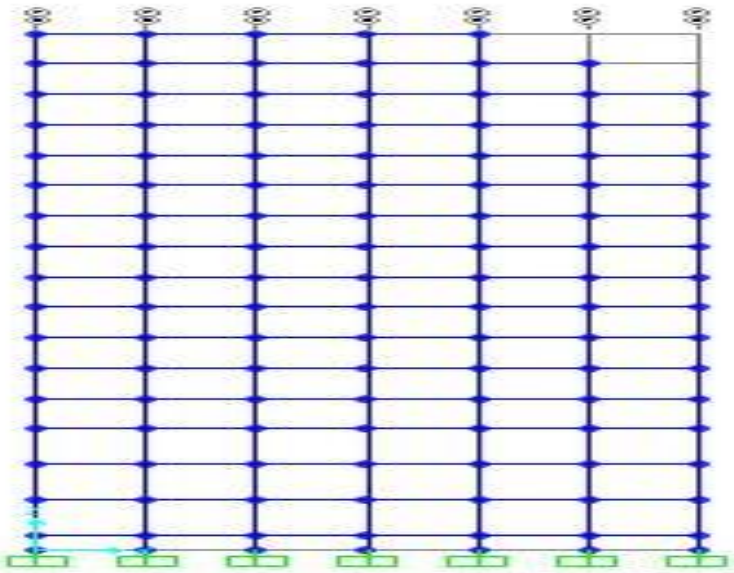

Fig. 2- Elevation of setback 1 building

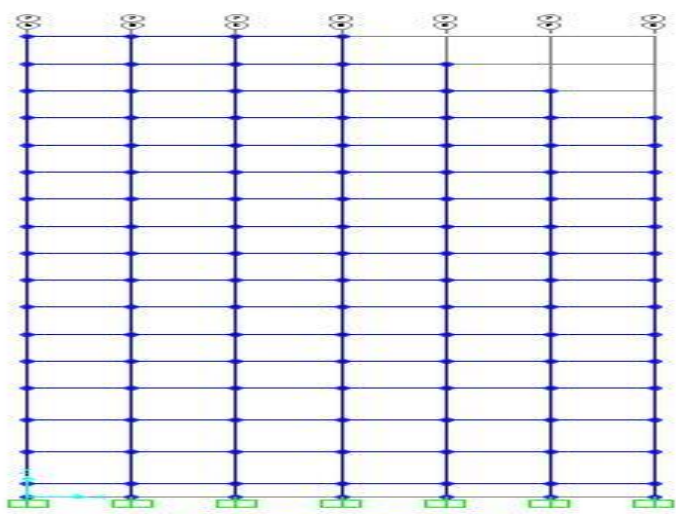

Fig. 3- Elevation of setback 2 building

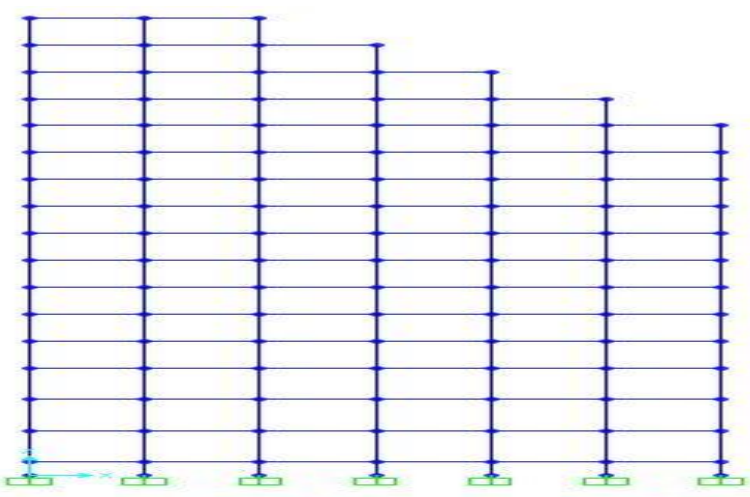

Fig. 4- Elevation of setback 3 building

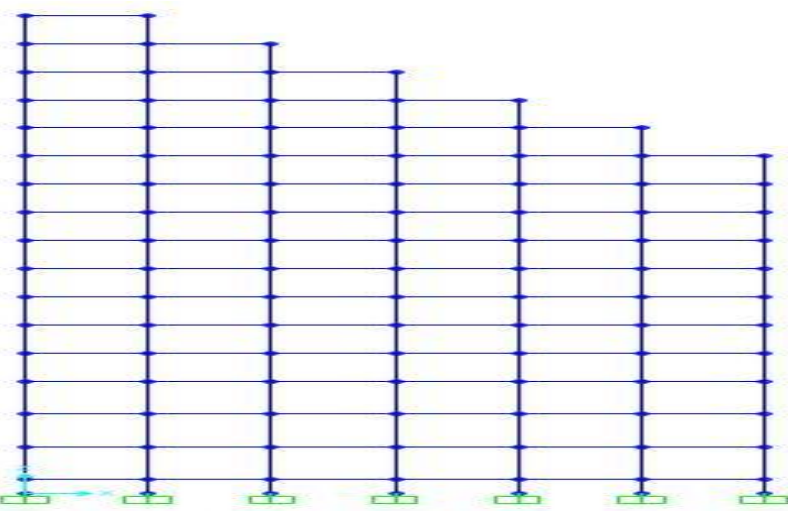

Fig. 5- Elevation of setback 4 building 


\section{Results and Discussion}

The models of different setbacks with mass and stiffness irregularity of G+16 building are analysed and compared by using software SAP 2000. These buildings are compared to find response against earthquake of the R.C building. Following results are obtained:

\section{A. Base Shear}

Table 1: Base Shear of SMRF building models in zone V along both X-X and Y-Y axis

\begin{tabular}{|l|l|l|}
\hline \multirow{2}{*}{ MODELS } & Base Shear in kN & Along Y-Y \\
\cline { 2 - 3 } & Along X-X & 1453 \\
\hline REGULAR & 1935 & 1606 \\
\hline SETBACK 1 & 1939 & 1597 \\
\hline SETBACK 2 & 1942 & 1582 \\
\hline SETBACK 3 & 1945 & 1556 \\
\hline SETBACK 4 & 1946 &
\end{tabular}

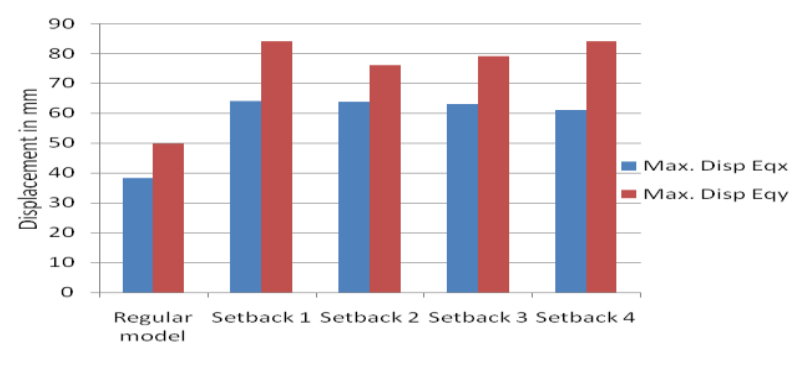

Fig. 6- Base Shear of SMRF building models along both X-X and Y-Y axis

\section{B. Lateral Displacement}

Table 1: Lateral Displacement of SMRF building models in zone V along both X-X and Y-Y axis

\begin{tabular}{|l|l|l|}
\hline \multirow{2}{*}{ MODELS } & Displacement in $\mathrm{mm}$ \\
\cline { 2 - 3 } & Along X-X & Along Y-Y \\
\hline REGULAR & 38.2 & 49.7 \\
\hline SETBACK 1 & 64 & 84 \\
\hline SETBACK 2 & 63.83 & 76 \\
\hline SETBACK 3 & 63 & 79 \\
\hline SETBACK 4 & 61 & 84 \\
\hline
\end{tabular}

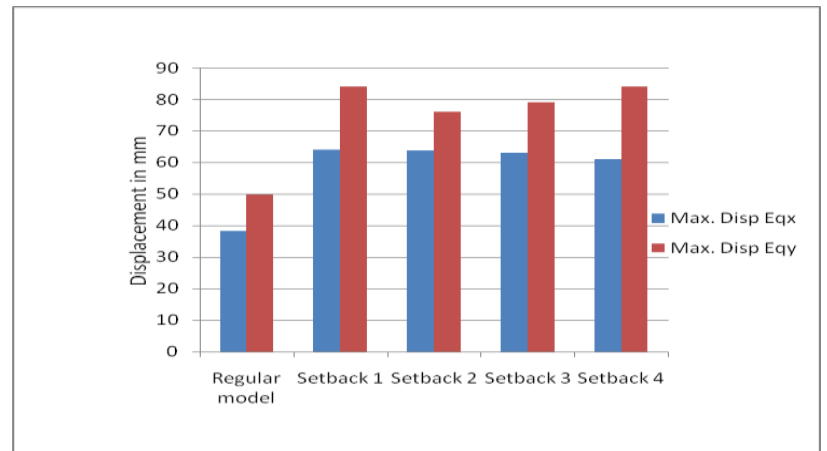

Fig. 7- Lateral Displacement of SMRF building models along both X-X and $\mathrm{Y}-\mathrm{Y}$ axis.

\section{Performance Point}

Table 3: Lateral Displacement of SMRF building models in zone V along both X-X and Y-Y axis

\begin{tabular}{|l|l|}
\hline MODELS & Performance Point \\
\hline REGULAR & 4569 \\
\hline SETBACK 1 & 7335 \\
\hline SETBACK 2 & 7363 \\
\hline SETBACK 3 & 7386 \\
\hline SETBACK 4 & 7453 \\
\hline
\end{tabular}




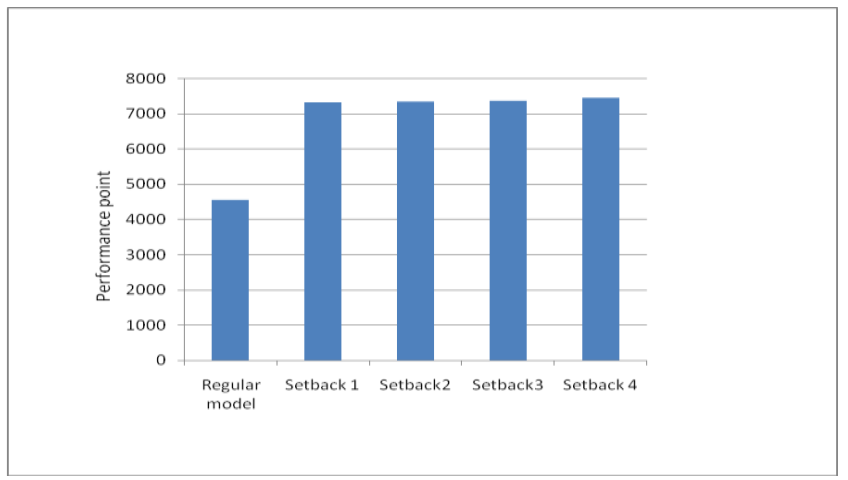

Fig. 8- Performance Point of SMRF building models

\section{Pushover Results}

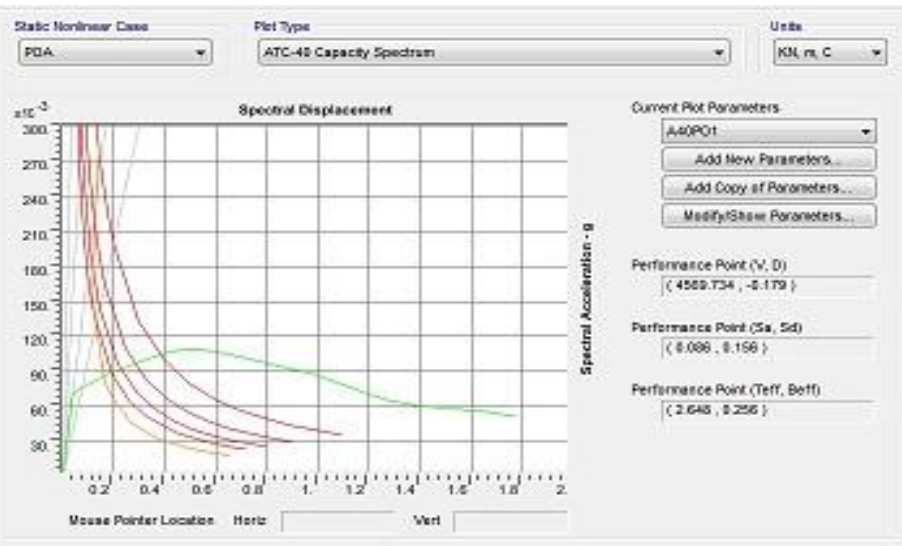

Fig. 9- Capacity spectrum curve for regular building

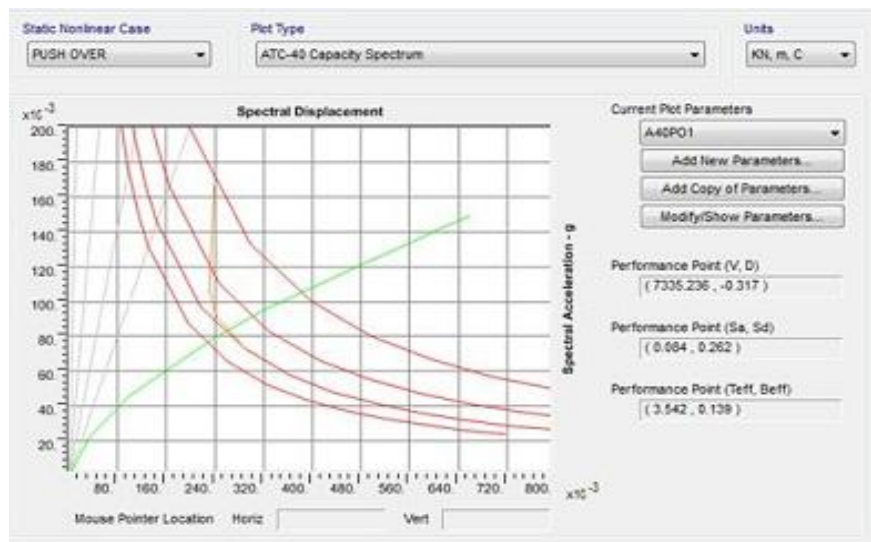

Fig. 10- Capacity spectrum curve for setback 1 building

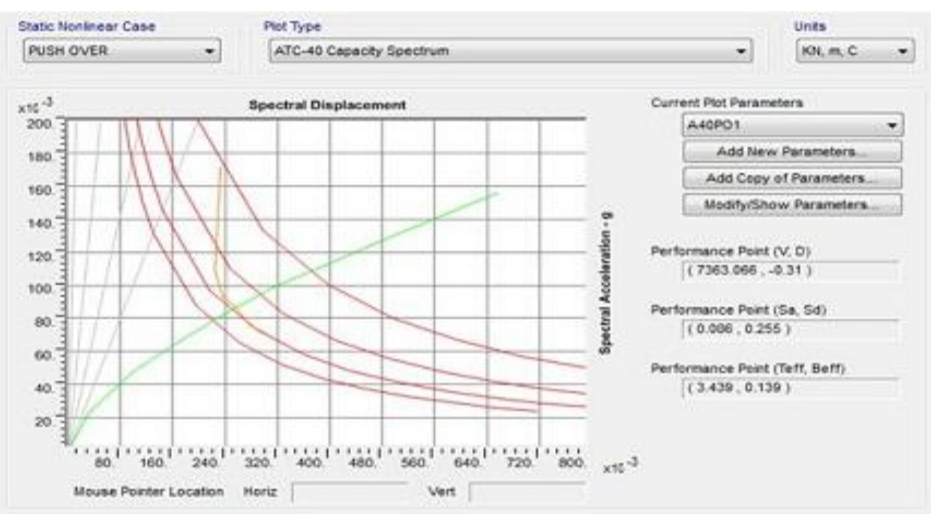

Fig. 11- Capacity spectrum curve for setback 2 building 


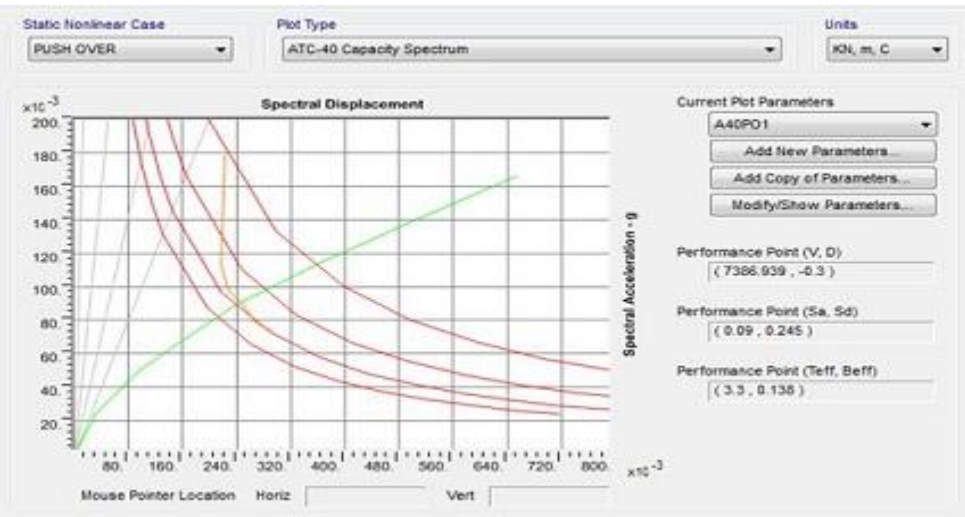

Fig. 12- Capacity spectrum curve for setback 3 building

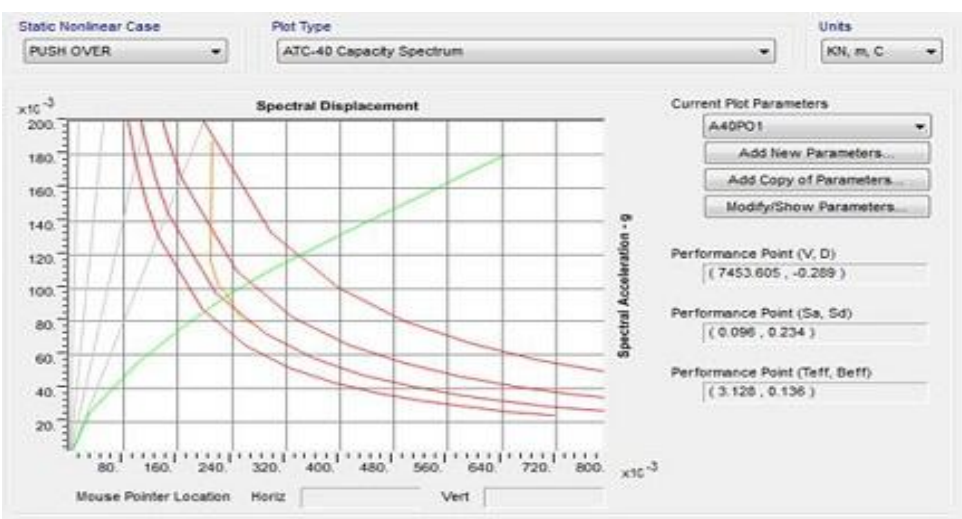

Fig. 13- Capacity spectrum curve for setback 4 building

\section{E. Hinge Results}
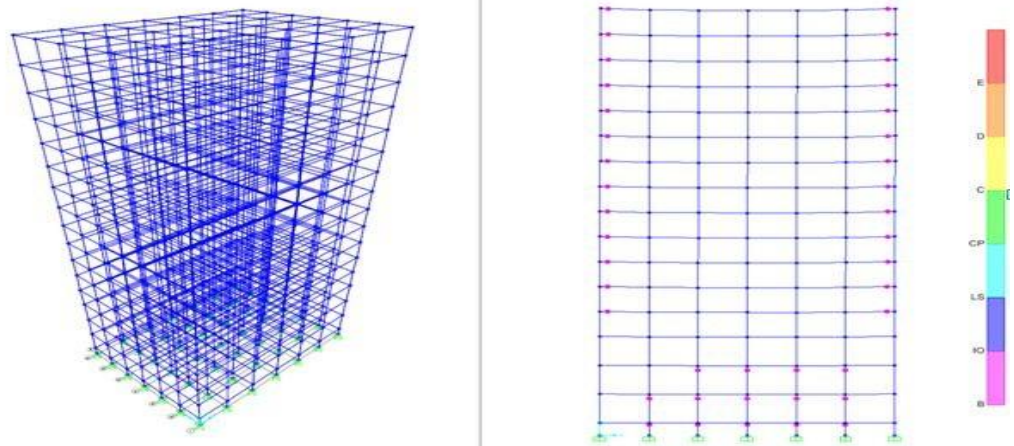

Fig. 14- Hinge formation for regular building
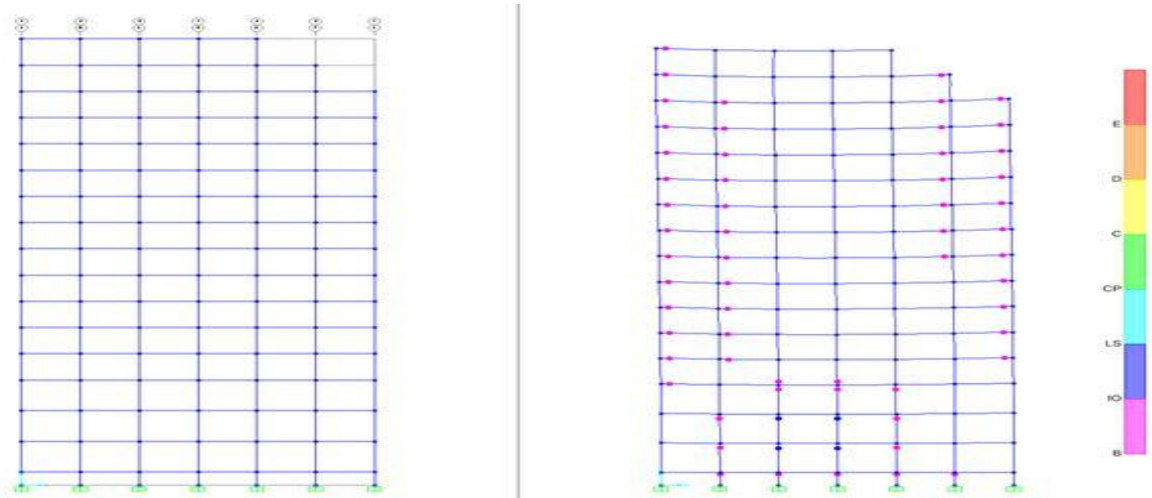

Fig. 15- Hinge formation for setback 1 building 

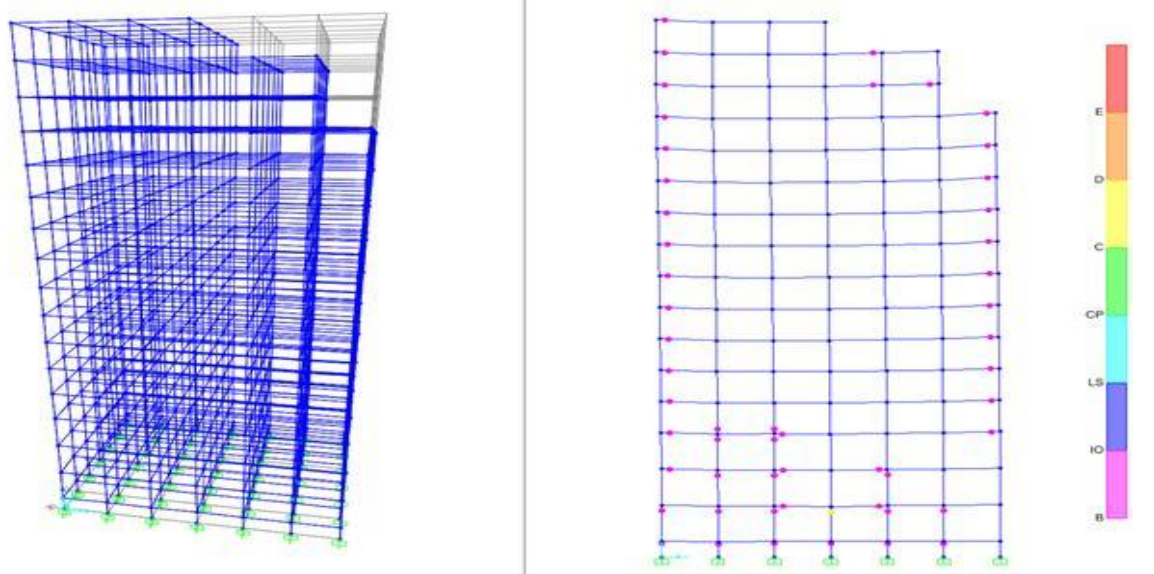

Fig. 16- Hinge formation for setback 2 building
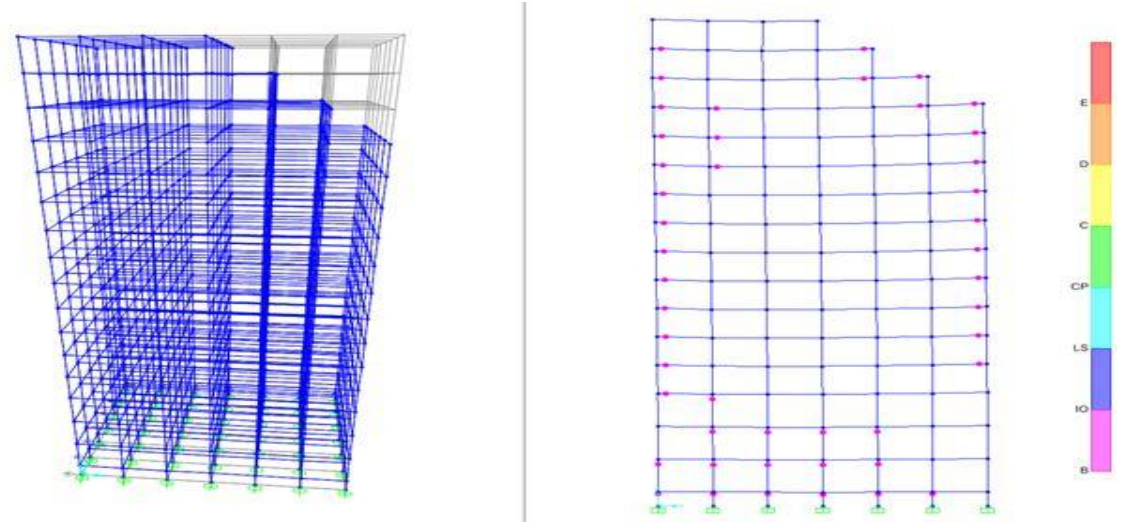

Fig. 17- Hinge formation for setback 3 building
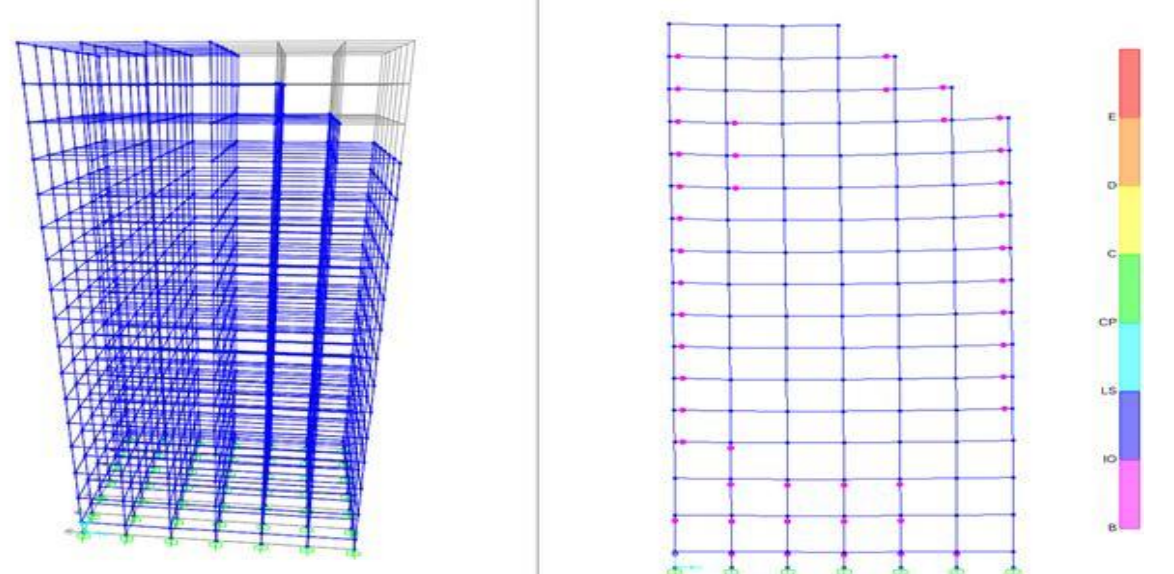

Fig. 18- Hinge formation for setback 4 building

\section{Conclusion}

The behaviour of RC framed structure with and without different vertical irregularities was investigated for the combination of vertical setback and vertical irregularities. This performance of building was analyzed by non linear static (Pushover) analysis in both $\mathrm{X}$ and $\mathrm{Y}$ direction.

Following were the major concluding drawn from the study.

1. The plastic hinges are formed at different stages B-IO, IO-LS, LS-CP, CP-C, D and E this zone levels based on performance level of building (ATC40), moderate, light, and very light to decided.

2. The frames without vertical irregularity having more lateral load capacity compare to frames with vertical irregularity. 
3. While comparing this frames with and without vertical irregularity, the vertical irregularity reduce the flexure and shear demand.

4. It is concluded that as the amount of setback increase, the critical shear force also increase. The regular building frames posses low shear force compared to irregular frames.

5. The seismic performance of regular frame is found to be better than the corresponding irregular frames in nearly all the cases.

6. Maximum lateral displacement is obtained in vertical irregular building and less in regular building.

\section{References}

[1] Nabiollah Alirahimi Kashkooli and Mahmoud-Reza Banan "Effect of frame irregularity on accuracy of modal equivalent nonlinear static seismic analysis" KSCE journal of civil engineering, Shiraz university, Shiraz, Iran (2013).

[2] Alinda Dey, Urmimala Bhattacharjee"Pushover Analysis for Multistory Building” KIIT University, Bhubaneswar, Odisha volume 2(2015)

[3] Mohommed Anwaruddin Md. Akberuddin, Mohd. Zameeruddin Mohd.Saleemuddin.’Pushover Analysis of Medium Rise MultiStory RCC Frame With and Without Vertical Irregularity" Nanded, ijera, volume 3 (2013).

[4] M. Pavan Kumar, Sateesh Konni "Effect of Vertical Irregularities of RC Framed structures by Using Non-Linear Static Analysis" SVCET, JNTU-K, AP, India, IJER Volume 4 (2015).

[5] Shaikh Abdul Aijaj Abdul Rahman and Girish Deshmukh "Seismic Response of Vertical Irregular RC Frame with Stiffness Irregularity at fourth floor" Nanded, India, IJETAE, volume 3 (2013)

[6] Dileswar Rana and Prof. Juned Raheem "Seismic Analysis of Regular Geometry Irregular RCC Framed Building” Bhopal, India, irjet, volume 2 (2015)

[7] Nuthan Pathi, Guruprasad T N, Dharmesh N and Madhusudhana Y.B”Static Linear and Non-Linear (Pushover) Analysis of Multy Storey RC Frame With and Without Vertical Irregularities" SIET, Tumkur, India.

[8] Nishant Rana and Siddhnat Rana"Non-Linear Static Analysis(Pushover Analysis) A Review” Meerut(U.P), India, IJETR, volume $3(2015)$ 